\title{
Age-Friendly Approaches and Old-Age Exclusion: A Cross-City Analysis
}

\author{
By Tine Buffel ${ }^{1}$, SAMuÈLE RÉMILLARD-BoILARD ${ }^{1}, K_{\text {IERAN WALSH }}{ }^{2}$, \\ Bernard McDonald ${ }^{2}$, An-Sofie SMetcoren ${ }^{3}$ E Liesbeth De \\ DONDER ${ }^{3}$
}

\begin{abstract}
Developing "Age-Friendly Cities and Communities (AFCC)" has become a key part of policies aimed at improving the quality of life of older people in urban areas. In spite of this development, there is evidence of rising inequalities among urban elders, and little is known about the potential and limitations of the age-friendly model to reduce old-age exclusion. This article addresses this research gap by comparing how Brussels, Dublin and Manchester, as three members of the Global Network of AFCC, have responded to social exclusion in later life. The article combines data from document analysis and stakeholder interviews to examine: first, the background against which age-friendly programmes have emerged in the respective cities; second, the extent to which the goal of reducing social
\end{abstract}

\footnotetext{
${ }^{1}$ Tine Buffel \& Samuèle Rémillard-Boilard, Sociology/Manchester Institute for Collaborative Research on Ageing (MICRA), Manchester Urban Ageing Research Group (MUARG), The University of Manchester, Manchester, the United Kingdom.

${ }^{2}$ Kieran Walsh \& Bernard McDonald, Irish Centre for Social Gerontology, Institute for Lifecourse and Society, National University of Ireland, Galway, Ireland.

${ }^{3}$ An-Sofie Smetcoren \& Liesbeth De Donder, Department of Educational Sciences, Vrije Universiteit Brussel (VUB), Brussels, Belgium.
} 
International Journal of Ageing and Later Life

exclusion is integrated in the age-friendly strategies; and third, barriers to the implementation of age-friendly programmes. The paper suggests that there are reciprocal benefits in linking age-friendly and social exclusion agendas for producing new ways of combating unequal experiences of ageing in cities.

Keywords: age-friendly communities, social exclusion, old-age exclusion, social policy, urban ageing.

\section{Introduction}

This article examines the potential of "age-friendly" city initiatives to reduce "social exclusion" in old age, drawing on the example of three European cities. "Social exclusion" is the process through which individuals and groups become deprived of the rights, resources and services available to most people in society (Levitas et al. 2007). In line with research on exclusion in later life, this paper defines social exclusion as a multidimensional concept, covering domains such as exclusion from material resources, services, social relations, neighbourhoods, and civic and sociocultural participation (Precupetu et al. 2019; Van Regenmortel et al. 2016; Walsh et al. 2017). We also recognise that exclusion is dynamic, and it varies in form and degree across the life course, with an increased prevalence and impact in later life, especially amongst those facing old-age vulnerabilities and those who have experienced cumulative disadvantages across their life course (Walsh et al. 2017; Prattley et al. 2020).

Reducing the number of people at risk of exclusion has been a central theme in European social policy, reflecting concerns about the social and economic costs when individuals and communities become cut off from the wider society (Eurostat 2017). Yet, enduring inequalities in the experience of ageing suggest that policies have had limited effect in reducing old-age exclusion (Nazroo 2017; Scharf \& Shaw 2017). Addressing this issue has become especially urgent given the impact of economic austerity and widening inequities within urban settings (Buffel \& Phillipson 2016, 2018).

Many older people are excluded from participating in society due to a combination of structural and environmental barriers (De Tavernier \& Aartsen 2019; Wanka et al. 2018). By promoting inclusive and accessible 
environments that are responsive to older adults' needs, "age-friendly" programmes can be seen as an effective approach to counter exclusion in later life (WHO 2018). The World Health Organization (WHO 2007) has been especially influential in developing the "age-friendly" perspective. In 2010, the WHO launched the Global Network of Age-friendly Cities and Communities (GNAFCC). Since then, the GNAFCC has had a rapid increase in membership, reaching over 1000 cities and communities across in the Global North and South by 2020. Members share a commitment to adapt their structures to the needs of their ageing populations, with attention to service provision (health services, transportation), the built environment (housing, outdoor spaces) and social aspects (civic and social participation).

These "age-friendly" domains suggest not only an overlap but also a possible response to the various forms of exclusion in later life, representing a shared focus in fostering the full participation of older people (Scharlach \& Lehning 2013; WHO 2018). In spite of these connections, little is known about the actual potential of the age-friendly model for reducing old-age social exclusion. In strategic terms, this means it is unclear whether or not we should increase investments in age-friendly programmes, as a means of enhancing the inclusion of disadvantaged older adults. The limited availability of meaningful cross-national comparative data compounds these issues and our ability to affirm common principles and success. It also impedes our understanding of the degree to which the age-friendly framework may serve as a transferable model to improve the multifaceted lives of older people across jurisdictions.

This paper reports on a comparative study of age-friendly strategies in three European cities, exploring the extent to which they address issues relating to social exclusion in later life. In doing so, the article addresses the following questions: to what degree is social exclusion integrated as a part of the goals of age-friendly strategies and policy documents in the respective cities? What projects and policies have been developed to respond to social exclusion in each city? What are the barriers to implementing age-friendly programmes that will affect the delivery of initiatives aimed at combating social exclusion? 
International Journal of Ageing and Later Life

\section{Research Design and Methods}

This study used a case-study approach, allowing for an in-depth investigation of "a contemporary phenomenon within its real life context, especially when the boundaries between a phenomenon and context are not clear and the researcher has little control over the phenomenon or context" (Yin 2002: 13). This method is effective to examine programmes or policies (Yin 2002), and has been shown to be particularly instrumental in exploring agefriendly strategies and initiatives (i.e. the cases) across different cities (i.e. the sites) (Rémillard-Boilard 2019). The benefits of such an approach are threefold: first, it can increase awareness of the policy options adopted by different cities/countries in combating exclusion (Buffel et al. 2014, 2018); second, it can improve our understanding of both the success factors and barriers to implementing age-friendly initiatives (Moulaert \& Garon 2016); and third, it is important in fostering "mutual policy learning across national borders" (Hantrais 2009: ix) about what is effective and what is not.

The research employed a purposeful and convenience sampling strategy (Patton 2002) to select three cities: Brussels, Dublin and Manchester. Three criteria guided the selection process. Cities were purposefully selected on the basis that they: (1) had adopted the WHO framework to structure their work around age-friendliness; (2) were amongst the first to become a member of the GNAFCC, reflecting their pioneering role in developing age-friendly programmes; and (3) were located in different countries. The opportunity to compare these cities arose from collaborative work between research teams focusing on age-friendly work in the respective cities, through the COST Action network "Reducing Old-Age Social Exclusion" (ROSEnet). This provided a unique opportunity to bring together existing qualitative data sets for new, comparative purposes. Combining different sets of qualitative data not only has the potential to "lend new strength to the body of fundamental social knowledge" (Glaser 1963: 11) but also "brings greater power to answer research questions" through comparison across contexts, social groups and cultures (Corti et al. 2005: 8).

Data were derived through a combination of policy documents and secondary qualitative data from interviews with stakeholders in each city. This approach facilitated both an understanding of the formal recognition of the connection between age-friendly work and social exclusion in strategic goals and descriptive statements, and an insight into an insider, more 
Age-friendly approaches and old-age exclusion

subjective, perspective of the degree to which age-friendly activities actually target, or have the potential to target, a reduction in social exclusion.

\section{Documentary Analysis}

Internal reports and official policy documents were analysed to provide background to the study and explore the extent to which social exclusion was integrated as part of the age-friendly strategies and policy documents in the respective cities. A first step in the documentary analysis was to find the relevant documents and assess their connection to the research questions. The documents were selected according to two criteria: material that referred to the city's ageing strategy from 2010 to 2018, and material that was developed in preparation for, or following the admission of the city to, the GNAFCC membership (see Table 1, Key documents guiding the development of the programme).

Based on the selected material, a preliminary document analysis was carried out by the lead researcher in the respective city, using qualitative content and thematic analysis (Bowen 2009). To enhance comparability between the cities' programmes, a common framework was agreed, using six key codes to analyse the documents: context analysis, key priorities and aims of the programme, key concepts, actions, and explicit and implicit links to social exclusion. Using this framework, the data were summarised into a matrix, and the frequency or number of occurrences of concepts and dimensions linked to old-age exclusion was documented for each city. A next step involved a face-to-face meeting between the cross-national author team to explore how the codes were interrelated to one another in each of the cities separately, as well as to identify similarities and differences in the policy responses adopted across the cities. Finally, the lead author produced analytic memos presenting the key findings for each of the cities, and these were subsequently discussed, adapted and agreed with other members of the research team.

\section{Secondary Data Samples}

In addition to documentary analyses, the authors of this paper also combined relevant data sets from their previous work in order to form a new secondary data sample for this study. Thus, data from stakeholder interviews in Brussels $(n=23)$, Manchester $(n=25)$ and Dublin $(n=27)$ were 
International Journal of Ageing and Later Life

Table 1. Characteristics of the age-friendly programmes

\begin{tabular}{|c|c|c|c|}
\hline & City of Brussels & City of Dublin & City of Manchester \\
\hline $\begin{array}{l}\text { Actor leading } \\
\text { age-friendly } \\
\text { work }\end{array}$ & $\begin{array}{l}\text { City Council } \\
\text { Senior Service }\end{array}$ & $\begin{array}{l}\text { City Council } \\
\text { Age-friendly } \\
\text { Alliance }\end{array}$ & $\begin{array}{l}\text { City Council } \\
\text { Age-friendly } \\
\text { Manchester Team, } \\
\text { Public health }\end{array}$ \\
\hline $\begin{array}{l}\text { Year the city } \\
\text { joined the } \\
\text { GNAFCC }\end{array}$ & 2010 & 2013 & 2010 \\
\hline $\begin{array}{l}\text { Key documents } \\
\text { guiding the } \\
\text { development } \\
\text { of the age- } \\
\text { friendly } \\
\text { programme }\end{array}$ & $\begin{array}{l}\text { - Plan Seniors } 2010 \\
\text { [Seniors Plan 2010] } \\
\text { - 'Plan Seniors 2015' } \\
\text { (tentative title, } \\
\text { the plan was not } \\
\text { adopted by the } \\
\text { council) } \\
\text { - Assemblée General } \\
\text { BXL 55+, Projects } \\
\text { Action, 2016-2018 }\end{array}$ & $\begin{array}{l}\text { - Age-friendly } \\
\text { Dublin. Dublin } \\
\text { City. A Great } \\
\text { Place to Grow } \\
\text { Old Age- } \\
\text { friendly Strategy } \\
\text { 2014-2019 } \\
\text { - Age-Friendly } \\
\text { Dublin, progress } \\
\text { report } 2016\end{array}$ & $\begin{array}{l}\text { Manchester: } \\
\text { A Great Place } \\
\text { to Grow Older, } \\
2010-2020 \\
\text { - Manchester: } \\
\text { A Great Place } \\
\text { to Grow Older, } \\
\text { 2017-2021. } \\
\text { Second edition }\end{array}$ \\
\hline $\begin{array}{l}\text { Research team } \\
\text { involved in } \\
\text { this study } \\
\text { exploring the } \\
\text { age-friendly } \\
\text { programmes }\end{array}$ & Anonymised & Anonymised & Anonymised \\
\hline
\end{tabular}

GNAFCC, Global Network of Age-friendly Cities and Communities.

drawn from multiple primary studies in the respective cities (see Table 2), all of which shared an interest in inclusion/exclusion and the participation of older people in the context of age-friendly initiatives. The shared focus of the primary studies provided us with a unique opportunity to explore the research questions across different contexts.

For Brussels and Manchester, interview data for the secondary study were derived from research conducted between 2015 and 2018 that 
Table 2. Secondary data samples

\begin{tabular}{|c|c|c|c|}
\hline & City of Brussels & City of Dublin & City of Manchester \\
\hline $\begin{array}{l}\text { Participants } \\
\text { (n) }\end{array}$ & $n=23$ & $n=27$ & $n=25$ \\
\hline $\begin{array}{l}\text { Duration of } \\
\text { interview }\end{array}$ & $\begin{array}{l}50-92 \mathrm{~min} \\
\text { Averaging } 69 \mathrm{~min}\end{array}$ & $\begin{array}{l}\text { 36-105 min } \\
\text { Averaging } 78 \mathrm{~min}\end{array}$ & $\begin{array}{l}43-89 \mathrm{~min} \\
\text { Averaging } 62 \mathrm{~min}\end{array}$ \\
\hline $\begin{array}{l}\text { Background } \\
\text { of } \\
\text { participants }\end{array}$ & $\begin{array}{l}\text { - Local authority } \\
(\mathrm{n}=5) \\
\text { - Voluntary } \\
\text { organisations } \\
(\mathrm{n}=4) \\
\text { - Statutory } \\
\text { services }(\mathrm{n}=5) \\
\text { - Policy specialists } \\
(\mathrm{n}=3) \\
\text { - Academia }(\mathrm{n}=2) \\
\text { - Community } \\
\text { stakeholders } \\
(\mathrm{n}=4)\end{array}$ & $\begin{array}{l}\text { - Local authority } \\
(\mathrm{n}=8) \\
\text { - Voluntary } \\
\text { organisations } \\
(\mathrm{n}=4) \\
\text { - Statutory services } \\
(\mathrm{n}=6) \\
\text { - Policy specialists } \\
(\mathrm{n}=4) \\
\text { - Private services } \\
(\mathrm{n}=1) \\
\text { - Community } \\
\text { stakeholders }(\mathrm{n}=4)\end{array}$ & $\begin{array}{l}\text { - Local authority } \\
(n=7) \\
\text { - Voluntary } \\
\text { organisations } \\
(n=5) \\
\text { - Statutory services } \\
(n=3) \\
\text { - Policy specialists } \\
(n=2) \\
\text { - Academia }(n=3) \\
\text { - Community } \\
\text { stakeholders } \\
(n=5)\end{array}$ \\
\hline
\end{tabular}

explored age-friendly policies and initiatives, and their relation to social exclusion (led by the first and second author). A maximum variation sampling strategy (Rapley 2013) was used to ensure that a wide range of research, policy and practice perspectives was captured across the cities. The interview guides included questions concerning the goals of the agefriendly programmes, and barriers and opportunities associated with implementing age-friendly initiatives.

Dublin data were derived from two primary studies involving interviews with stakeholders: first, a research study (led by the third author) aimed at reimagining communities for vulnerable groups of people (including older adults) in three Irish cities (The 3-Cities Project - fieldwork completed in 2014); and, second, a project (led by the fourth author) exploring the implementation of an age-friendly programme in Fingal, an administrative area within Dublin County (fieldwork completed 2014-2016). 
International Journal of Ageing and Later Life

Both studies addressed topics reflecting different domains of exclusion, including civic participation, services and neighbourhood exclusion.

While the original research protocols for data collection in the three countries were not codeveloped or designed to follow the same protocols, the author team had broadly contributed to the development of each of the primary studies, through network meetings and feedback/review sessions. The three city samples, in three different countries, also point to the similarity in stakeholder participants (see Table 2). All primary studies received ethical approval from their respective home institutions. The secondary analysis was conducted according to University's code of ethics and good research practice.

\section{Secondary Data Analysis}

The secondary analysis involved the reanalysis of the stakeholder interviews for the purpose of answering new research questions that were not part of the primary analysis (Ruggiano \& Perry 2019). All interviews were audio-recorded and transcribed verbatim as part of the primary studies in the respective cities. Using a thematic content analysis approach, the secondary analysis involved three steps (Corti et al. 2005). First, the reading of the three sets of interviews was completed by the lead researchers involved in the respective primary studies, noting how the coding strategy and labels used in the primary study related to the secondary study, with the aim of developing the same coding schedule across all interviews. In order to increase the credibility of the analysis approach, the coding frame for the secondary study was subject to systematic review by all authors and refined through a process of consensus (Ruggiano \& Perry 2019).

The second step of the secondary analysis entailed the coding of each interview on the basis of the jointly agreed conceptual framework, as well as directly from the interview data. Sixteen codes were identified, including "aims and priorities of age-friendly strategies," "definitions of social exclusion," "projects tackling old-age exclusion," "economic austerity," "bureaucratic structures and interagency collaboration," "sustainability" and "measuring impact." Third, a two-day face-to-face meeting was held between the author team to review thematic codes and cluster pre-existing codes into key themes common to each dataset (Silverman 2006) (such as "barriers to implementing age-friendly programmes" and "approaches 
Age-friendly approaches and old-age exclusion

to reduce social exclusion"). The team then jointly reread the interview data across the three cities, to refine and verify the overall themes to achieve validity in the findings. The aim was to further identify whether or not there were any specific patterns with regard to the key themes identified in each of the cities.

\section{Findings}

In the following sections, the main findings are presented within four overarching themes. The first section provides the background against which the age-friendly programmes have emerged in the respective cities. Second, the paper examines whether and how the goal of combating "social exclusion" is integrated into the age-friendly strategies in Brussels, Dublin and Manchester. The third section reviews various age-friendly projects and initiatives that have focussed on reducing one or multiple domains of social exclusion. Finally, the paper identifies four interconnected challenges to implementing age-friendly programmes based on the stakeholder interviews in the respective cities.

\section{Emergence of the Age-Friendly Approach}

The analysis suggests that in all three cities, the political context was favourable to the emergence of new proposals and frameworks at the time the age-friendly approach was adOpted by the respective local councils. Becoming a member of the WHO GNAFCC was seen as the formal start of the respective cities' age-friendly programme, following a commitment to develop an inclusive baseline assessment of the age-friendliness of the city and an action plan based upon the assessment's findings aimed at improving both the physical and the social environment. However, the analysis also highlighted differences in the way the age-friendly approach emerged on the political agenda, which will be described below.

In Brussels, the age-friendly approach was initiated in 2007 by the city's councillor responsible for ageing issues who used the WHO framework as a way of expanding the council's programme of work for older people. Until then, population ageing had been given limited policy attention, which was attributed in part to the relatively young age structure of the city. In collaboration with the Belgian Ageing Studies (BAS) research 
International Journal of Ageing and Later Life

group in Brussels, the council conducted a baseline assessment for the city in 2009, using a participatory methodology involving older people in all stages of the study. The results enabled the council to develop a framework for action, which served as the basis for the city's application to become a member of the GNAFCC in 2010. In line with the WHO framework, the Brussels' age-friendly strategy (2010) focussed on various domains of city life, including community safety, housing, mobility, participation, information and health, with a range of initiatives identified for each domain. Joining the GNAFCC was seen as a way of reaffirming the council's commitment to the ageing agenda and ensuring the sustainability of the Senior Services (the administrative body responsible for older people) and the Council of Seniors (an advisory body comprising older residents) that had recently been developed.

Whereas Brussels was the first and one of the few cities in Belgium to join the Global Network at the time of the study, the Dublin Age Friendly Initiative began in 2013 amidst widespread adoption and endorsement of Age-Friendly programmes across Ireland (McDonald et al. 2018). This development took place against the backdrop of the Dublin Declaration on AFCC in 2011, Ireland's membership of the GNAFCC as one of the original ten affiliated states and the efforts of Age Friendly Ireland, a philanthropic funded organisation, in developing the national programme. It also developed in the context of the Revitalising Areas by Planning, Investment and Development (RAPID) programme, a central government initiative, which since 2001 had focussed on tackling social inclusion and disadvantage in nine deprived areas in the city. The Dublin Age Friendly Strategy 2014-2019 comprised nine strategic goals around key themes, including outdoor space and buildings; transport; home and community; safety; social, economic and political life; and healthy and active living. The initiative was led by the city council and supported by a high-level inter-agency and cross-sector (public, private, voluntary) City Alliance and five local area alliances, aligned with Dublin City Council's five administrative areas. An older person's council had been formed in each area to inform the decision-making of Dublin's age-friendly programme.

Compared to Brussels and Dublin, Manchester had a somewhat longer tradition of developing work aimed at improving the quality of life of older people in the city. The origins of Age-Friendly Manchester can be traced to the Valuing Older People (VOP) project in 2003, a strategic cross-sector 
Age-friendly approaches and old-age exclusion

partnership to promote the participation and engagement of older people, with a range of projects across the city, including local neighbourhood networks, and a campaign to promote a more positive image of older people. Building on this work, Manchester became the first city in the United Kingdom to join the GNAFCC in 2010, with VOP rebranding itself as the "age-friendly" programme now located in the newly established Public Health Manchester Service in Manchester City Council. Since its membership of the GNAFCC, Manchester had developed a number of key documents to guide its work, including a 10-year strategy (2010-2020) and the Age-Friendly Manchester's refreshed strategy (2017), which identified three priorities: first, to develop age-friendly neighbourhoods; second, to create age-friendly services; and third, to promote age equality to reduce ageism and address the negative image of ageing. As with Brussels and Dublin, Manchester had an Older People's Board to promote the voice of older residents in decision-making.

\section{Age-Friendly Strategies and the Goal of Combating Social Exclusion}

The documentary analysis showed that the goal of "combating social exclusion" was integrated into the age-friendly strategies of all three cities, albeit in different ways. Tackling exclusion was mentioned as an explicit goal in the case of Manchester, whereas Brussels and Dublin demonstrated a commitment to reducing certain forms of exclusion whilst no explicit reference was made to the "social exclusion" concept. As for the latter, the age-friendly programmes in Brussels and Dublin shared a focus on challenging exclusion from social relationships, through their commitment to reduce social isolation and promote community participation.

Tackling the social isolation of older people had been a key priority of the Senior Service in Brussels since the start of the programme. Brussels did not have an official action plan to guide the development of its agefriendly work at the time of the study; however, the Senior Service had developed a brochure, reflecting its priority to promote community participation, which advertised age-friendly leisure, sports and social activities, and was distributed by post to older residents across the city. "Active ageing" or the idea to optimise opportunities for health and participation 
International Journal of Ageing and Later Life

was mentioned as a key principle guiding the work in Brussels in this brochure. In a similar fashion, the Dublin City Age Friendly Initiative was dedicated to "improving the quality of life of older people by including older people in decisions which affect their lives; providing opportunities that enable older people to live full and active lives" (Dublin Age Friendly City 2014). Building on the National Action Plan on Social Inclusion 20072016, the Dublin Age Friendly Strategy identified "inclusion" as one of the core values underpinning its work; this defined as "recognis[ing] the diversity of older people and advancing equality of participation for older people in the city" (p. 13). As with Brussels, a major orientating principle was that of "active ageing," or removing barriers to (or exclusion from) participation in social, cultural and sports activities in later life (Dublin Age Friendly City 2014).

Social exclusion was an explicit focus of the Manchester Strategy for Ageing (2017):

A significant number of Manchester's older residents experience high levels of social exclusion, which means they live in poverty, and are excluded from social relationships, civic relationships, basic services, and their neighbourhood. (p. 16)

Social exclusion here was defined as a multidimensional concept, with a particular "focus on those who are most disadvantaged" facing multiple forms of exclusion. Within the Manchester age-friendly programme, ensuring the social inclusion of older people in their communities, and tackling neighbourhood exclusion, had been long-standing themes, in part because of the high levels of deprivation in urban neighbourhoods. The focus on social exclusion had also been reinforced through collaborations between the Council and researchers, highlighting the social exclusion of older residents living in deprived urban neighbourhoods in Manchester (Phillipson 2007; Scharf et al. 2005).

\section{Age-Friendly Initiatives Aimed at Reducing Social Exclusion}

The analysis revealed a number of age-friendly projects and initiatives that had a focus on reducing one or multiple domains of social exclusion. These can be grouped into three categories: projects aimed at (a) promoting participation, (b) combating social isolation and (c) reducing 
neighbourhood exclusion. In terms of the first, all three cities had set up an Older People's Council as part of their age-friendly programmes to encourage the participation of older residents and older people's organisations in decision-making. In Brussels, the "Council of Seniors" had an advisory role and consisted of several working groups, reflecting the key domains of an age-friendly city. Local authority representatives emphasised the importance of having different voices represented and described the Council of Seniors "as one of the most participative mechanisms for older people we have." In a similar fashion, the Older People's Council in Dublin reflected the local authority stakeholders' commitment to "involve older people in the initiative" and ensure that their "lived experiences inform age-friendly developments" (Local authority representative and representatives from the Older People's Council). Manchester had two mechanisms to encourage the participation of older people in the age-friendly programme: an Older People's Board, including local older residents with an advisory role, and an Older People's Forum, a consultative body providing opportunities for older people and organisations to voice their questions, concerns and advice directly to decision-makers. As was the case for Older People's Councils in Brussels and Dublin, however, there was an underrepresentation of minority groups and those facing social exclusion in Manchester's older people's Board and Forum, in spite of a strong commitment to be "inclusive":

We want to engage a slice of the city, we want to engage, you know, BAME(Black, Asian and MinorityEthnicgroups),LGBT(Lesbian, Gay, Bisexualand Trans) groups, every...sokindof targetingquiteselectgroupsofolderpeopleandensuringthatwehaverepresentedallolder people...tomakesurethattheyallfeelrepresented by this[age-friendly]strategyand theyare

happy with the direction this is going in. (Manchester, Local authority representative)

Other examples of age-friendly initiatives aimed at promoting participation were those framed under the banner of "active ageing." The Age Friendly Dublin Programme, for example, had played a crucial role in promoting initiatives such as the "Let's walk and talk" project to encourage people to participate in walking activities while learning about local history and meeting new people. This was reported to provide health benefits and serve as an important source of inclusion for isolated individuals 
International Journal of Ageing and Later Life

by some stakeholders involved in the research, but no references were made to studies or evidence to support this claim.

"Active Ageing" was also found to be a priority of the Brussels agefriendly strategy, with range of initiatives targeting older people's participation in sports and exercise:

We installed fitness bikes in the parks; ensured that seniors had a discount in sports clubs; stimulated clubs to be more open to seniors; and offered seniors [subsidised] sports-cheques [to remove financial barriers]. We are also exploring the idea of 'exercise on [doctors'] prescription' with sports coaches offering personalised exercises in older people's homes or in the community.

The above quote and the focus on "active ageing" was illustrative for the target groups that were prioritised in the age-friendly programme in Brussels, that is, the more active and autonomous groups of older people. Indeed, the Brussels' programme gave limited attention to older people requiring assistance and care or those considered vulnerable in some way. The programme also made limited contact with the different migrant groups within the city's older population. Given the diversity in Brussels (with $62 \%$ of the population with a migration background, and $54 \%$ of this foreign population [a third of the total population] from outside the European Union), this was recognised as a major limitation by a number of community stakeholders.

A second category of initiatives was aimed at combating social isolation. Examples of flagship projects here included the Culture Champions Scheme in Manchester, an initiative involving 150 older volunteers (Cultural Champions) who aim to mobilise socially isolated groups of older people to participate in the city's cultural offer. Age-Friendly Manchester also aimed to reduce isolation in later life by addressing the needs of various groups within the older population, for instance, through the development of the United Kingdom's first lesbian, gay, bisexual and transgender (LGBT)-majority extra care specialist housing scheme. Other examples came from the Ambition for Ageing (AfA) programme, a $£ 10.2$ million National Lottery-funded Greater Manchester level programme, with a focus on tackling social isolation amongst older people living in low-income neighbourhoods. Ambition for Ageing's belief was that a series of small changes within communities will bring large-scale success in a practical and sustainable sense, which will ultimately help to reduce 
Age-friendly approaches and old-age exclusion

social isolation. This was done by providing small investments to groups of older people, with the aim of widening social networks and increasing the range of activities in the places in which people live.

Tackling the social isolation of older people has been a key priority since the start of the Brussels' age-friendly programme. To support this, the council had built six new community centres for older people across the city in 2018 ("Espace S pour les seniors"). These centres offered a range of social activities free of charge such as cooking, exercise classes, coffee mornings and workshops. Creating such opportunities for social participation had been identified as a priority because of the links with financial exclusion and housing-related problems, arising from inadequate housing stock and pressures from European institution office development and gentrification. A local authority representative described these Espace S centres as: "spaces where local residents can meet. They are neighbourhood-orientated and managed in a participatory way to better respond to the needs of older people in the neighbourhood." The delivery of the age-friendly programme in Brussels had mainly occurred through these community centres, and local authority representatives reported an increase in the use of and activities organised in those community hubs, but there had been no formal evaluation of their impact on reducing social isolation in later life.

Third, the analysis identified initiatives aimed at improving aspects of the built environment to reduce neighbourhood exclusion. For example, the Dublin Age Friendly Programme had committed to the development of a new demonstrator model - the Housing with Support Scheme - that prioritised accessibility and the needs of older residents. The project aimed to serve as an exemplary project for future housing and urban development initiatives, building upon principles of life-time adaptable housing, autonomy of choice and ageing in place. Plans were in place for a multi-phased evaluation of the scheme at the time of the study (see Walsh 2018), which included research into the experiences of older people who moved into the new housing development. Another example was found in Skerries, north of Dublin City, where 25 older residents were recruited to undertake a walkability study that subsequently informed the development of footpaths, pedestrian crossings, public seating and transport facilities. The town was awarded a national age-friendly town environmental award in 2015 for its successes in improving access to services 
International Journal of Ageing and Later Life

and amenities for older people. The award also recognised the improvements made in the social environment, including the establishment of a befriending scheme, increased support for older carers and the development of an information pack on local services, clubs and amenities.

The "Age-Friendly Old Moat Neighbourhood" research project was a similar initiative in Manchester, bringing together a housing association, the local authority, the Manchester School of Architecture and older residents (White et al. 2013) to improve the age-friendliness of a neighbourhood traditionally associated with poverty and high levels of social exclusion. The research has led to $£ 730 \mathrm{k}$ being invested in local projects between 2012 and 2018, with older people involved in designing aspects of the neighbourhood, including outside seating, social infrastructure and green spaces. Significant achievements included: a "Take a Seat Campaign," which engaged retailers to provide older people with a seat, access to a toilet and a glass of water on request; improvements to signage to assist older people in navigating the area; the organisation of a range of events and activities in community venues or people's own homes to reduce social isolation; and the design of adapted and accessible gardens to encourage older residents back into their gardens, providing raised beds and food growing support. These changes were reported to have a significantly positive impact on the lives of the housing association's tenants.

\section{Challenges to Implementing Age-Friendly Programmes}

Four interconnected challenges to implementing age-friendly programmes were identified in the analysis, including economic austerity, bureaucratic structures and interagency collaboration, sustainability and measuring impact. Unless otherwise specified, these barriers were generally shared across all cities.

\section{Economic austerity}

Economic austerity, as a result of the global economic crisis, was the most significant challenge for stakeholders, impacting the implementation of age-friendly programmes in each city. While in some instances circumstances had improved in recent years, in others the effects of austerity left a lasting legacy for stakeholders to contend with. 
In Brussels, public spending on health and social care had stagnated due to the global recession. Stakeholders highlighted the need for more investment to secure the availability of (semi)residential services, especially in densely populated and deprived urban districts. Sustaining successful pilot projects with limited resources was also identified as a key issue. A community worker on an intergenerational housing project highlighted that this was particularly felt when projects focussed on supporting vulnerable groups:

We need to start thinking about how to move forward because in less than a year's time, we'll run out of funding. It is expected that the group will be self-sustaining at the end of the project, so we're forced to slowly withdraw and shift responsibility to the residents. But it's a tricky process, especially with people who are vulnerable and may need support to take on such responsibilities.

In Dublin, the age-friendly programme was initiated at a time of severe recession in Ireland (McDonald et al. 2018). Major cutbacks to public health and community-based social services were introduced contemporaneously with the development of the programme. This included not only cuts to the budgets of key partner agencies but also reductions in community care provision, fuel and telephone allowances, community transport schemes and the closure of local services (Walsh 2015). Several stakeholders commented on the significant challenge of having to mobilise people and organisations under these constraints:

You've got very difficult times at the moment with all the cutbacks that have happened. So you're asking a very busy person to do an even busier job. I find it more difficult to get buy-in from people when they just feel overwhelmed, it's a huge [challenge].

In Manchester, public services, such as libraries, information centres and day care facilities, had been reduced due to budget cuts in the wake of the financial crisis. While these developments in themselves impeded plans to promote the city's age-friendly agenda, direct funding for the Age-Friendly Programme in the period 2013/2014 and 2014/2015 was reduced by $50 \%$ (Buffel \& Phillipson 2016). Consequently, both the scale of the programme and its core team contracted, with an important group of staff taking voluntary severance schemes from the local authority. 
International Journal of Ageing and Later Life

\section{Bureaucratic Structures and Inter-Agency Collaboration}

Bureaucratic structures and inter-agency collaboration were considered to be challenges to different degrees in each city. In Brussels, this took the form of specific political barriers that limited the potential of age-friendly work. This was summarised by a local authority representative: "It is the complexity of the political structures." A policy expert highlighted how such complexity was manifest in a number of ways:

Brussels is very complicated politically. There are five different ministers responsible for aspects of social care, plus a coordinating minister at the level of the Flemish Region and another for the Walloon region, as well as the City Council of Brussels and the Social Services. And nobody talks to each other... Organisations work in their own area, in their own perspective, and their own language. They don't communicate with each other, on the contrary, they compete with each other.

Reflecting some of the austerity-driven cutbacks, analysis in Dublin highlighted difficulties in terms of inter-agency partnerships. These included pressures in relation to recession-induced organisational downsizing, such as those that were identified as impacting on the national health agency - the Health Service Executive (HSE) (McDonald et al. 2018). Some stakeholders recognised the need for integrated service delivery but doubted if the Irish public service was in an appropriate state to operate as envisaged in the age-friendly programme:

You have to be cognisant of the fact that people don't have a huge amount of time, particularly at local authority level and HSE with all their embargoes on staffing and everything, and the big departure a few years ago of senior staff you know. Capacity shrank but the work didn't. (Representative of voluntary organisation)

\section{Sustainability}

Concerns about the sustainability of the age-friendly programme in each city were pervasive in stakeholder accounts, and were often connected to the first two challenges. Funding and budgets continued to be a general issue, but it was the impact that austerity cuts had on organisational capacity and know-how that was often highlighted. For instance, a Manchester local authority representative highlights the impact of the loss of staff, and their skills and networks, during the earlier budget cuts: 
Age-friendly approaches and old-age exclusion

There were massive restructures in local government, huge cuts, lots of people left under severance schemes. A lot of the networks that we'd built up almost disintegrated overnight.

In Dublin, pressures due to local government reform had produced similar issues. While political leadership proved crucial, individual leadership in the public service was also considered critical to sustainability. When this leadership was lost due to people moving roles, there was a risk that the programme itself could lose momentum:

A lot depends on the attitude of a manager locally... When people change - as in the public service people do - if the new person isn't bringing the same level of commitment, it can slip away.

However, in spite of these difficulties which were the result of austerity measures, the Dublin City Age Friendly programme was eventually integrated fully into local government mainstream structures in 2016.

In Manchester, there had also been positive developments in terms of sustainability. Since 2016, the devolution of powers had put Greater Manchester (GM) in charge of improving the health and well-being of those living in the region, bringing additional resources to the local level. The GM Ageing Hub, a group of leading policymakers, third sector representatives and researchers, responsible for developing policies to respond to demographic change across the region, was seen as essential for developing local partnerships:

We have these locality partnerships and Greater Manchester is one of them, and that's about putting a lot more resources [towards] one urban area where we know we have got momentum to work on ageing.... (Centre for Ageing Better)

As a consequence, even with significant implementation barriers in times of austerity, Manchester had been able to expand and raise the ambition of the urban ageing agenda. It had been able to secure much-needed political support for the programme from the outset, and develop partnerships to extend the reach of its programme into a broader city region (McGarry 2018). The city is now at the forefront of an ambitious city-regional approach to age-friendly development in GM, the first of its kind in the United Kingdom. 
International Journal of Ageing and Later Life

\section{Measuring impact}

In spite of the expansion of the age-friendly programme in the three cities, efforts to measure the impact of such initiatives had been limited, leaving major questions unaddressed, including: what contribution the approach makes to the quality of life of older people; whether it benefits some groups more than others; and whether it leads to improvements in urban environments. Establishing answers to these questions will be vital if local authorities are to extend financial support to age-friendly programmes (see, also, Golant 2014; Moulaert \& Garon 2016; Scharlach 2017). Stakeholders across the three cities understood the need to evaluate their programmes and measure their impact but recognised the significant challenge in designing and implementing appropriate approaches under current resourcing.

In Dublin and Brussels, and as with the vast majority of age-friendly initiatives (Buffel \& Phillipson 2018), local survey evidence was used to support the local implementation of age-friendly strategies, but a formal evaluation of the programme had yet to be completed. As one stakeholder from Dublin commented:

I think it's our next big challenge, I don't think we've licked it [measuring outcomes]... I think if we had the methodology and the funds to do that assessment.

The Age-Friendly Manchester team had plans to develop a framework that enhances systematic evaluation of the impact of its work. The aim was to inform the future development of the programme by both using existing data and collating new information about older residents. At the time of the study, a number of benefits had been associated with Manchester's age-friendly work, including the increased voice and visibility of older people and an increased participation in decision-making. The importance of monitoring and evaluation was mentioned by different stakeholders, and progress had been reported in relation to the evaluation of particular programmes (i.e. the AfA Programme, see above) linked to the age-friendly work. However, it was generally accepted that further development of tools that can support self-assessment, monitoring and evaluation was urgently needed. 
Age-friendly approaches and old-age exclusion

\section{Discussion}

This study represents the first attempt to explore the challenges and opportunities of the AFCC model to reduce social exclusion in later life across three city contexts. Addressing this issue has become especially urgent given the impact of economic austerity and widening inequalities within urban environments (Buffel \& Phillipson 2016, 2018).

The analysis identifies a number of factors that stimulate age-friendly strategies to respond to old-age exclusion. These include political support, strategic partnerships with multiple stakeholders, and mechanisms that facilitate the participation of older people in decision-making. A significant issue in this respect is the recognition that older adults are not just the beneficiaries of age-friendly communities but can play a key role in their development (Menec et al. 2011). Such factors were evident to some degree across the three cities, and have contributed to the survival - in some cases the growth - of the age-friendly movement in the context of economic austerity. The value of such attributes to efforts in combating social exclusion is also clear.

The research highlights a number of different age-friendly initiatives, with a focus on reducing one or multiple domains of exclusion across the three cities. These include, first, projects aimed at promoting the participation of older people in sports and "active ageing" activities on the one hand and in decision-making through the Older People's Councils on the other. A second category includes initiatives aimed at combating social isolation through creating community spaces and social infrastructure where older people can meet, socialise and volunteer. A third group of initiatives is aimed at reducing neighbourhood exclusion through involving older people in improving and designing aspects of the built environment responsive to the variety of needs within the ageing population.

The paper shows that such initiatives targeted at improving particular "age-friendly" domains (e.g. promoting social participation) provide a response to related forms of social exclusion (e.g. exclusion from social relationships). Given the linkages across the conceptual frameworks of exclusion and age friendliness, and the domains they both focus on, the argument developed here is that the concept of "social exclusion" provides a useful frame to assess the value of "age-friendly" programmes. 
International Journal of Ageing and Later Life

A number of benefits can be identified in linking age-friendly work to a central goal of reducing social exclusion in later life, in terms of: first, reaching out to those "left behind"; second, connecting age-friendly work with other major urban agendas; and third, providing a much needed orientation for age-friendly programmes, which can be the basis for monitoring and evaluation of outcomes and impact. Addressing these, the paper argues, will have the potential to expand and raise the ambition of the age-friendly agenda in a difficult economic climate with competing demands for resources.

A first advantage of linking age-friendly work to the goal of reducing social exclusion is that it will help to recalibrate age-friendly programmes, so that their focus is concentrated on those experiencing multiple forms of disadvantage and those most at risk of being excluded. This is in line with calls made by the WHO in its "Decade of Healthy Ageing 2020-2030" strategy and with the United Nations Sustainable Development Goals (2019) to "leave no one behind" and endeavour to reach those furthest behind first. However, as our analysis has shown, there are still groups of older people who tend to be underrepresented in age-friendly initiatives. A relevant question here is: "do age-friendly initiatives reach out to people with all types of health conditions or are they focused predominantly on the 'healthy', that is, those involved in different forms in terms of involving 'active aging'?" (Golant 2014). The findings from this paper suggest that whilst progress has been made in terms of involving diverse groups of older people, it is mainly the latter group who has dominated the development of age-friendly initiatives in the three cities. But this raises questions about whether the goal is to create "inclusive" rather than "exclusive" communities (Gonyea \& Hudson 2015). If the former, then age-friendly initiatives must have the capacity to support people diagnosed as "frail" or with dementia and associated conditions (Grenier 2007), and acknowledge the variety of groups for whom age-friendly issues are relevant.

Employing a central focus on reducing social exclusion is also likely to lead to consideration of the need to reach out to groups that may be disengaged from age-friendly issues. The age-friendly initiatives reported in this study have mainly drawn upon organisations already involved in campaigns on issues affecting older people, such as voluntary bodies working on behalf of older people, pensioner action groups and carers' organisations (Steels 2015). But these may have limited connections 
Age-friendly approaches and old-age exclusion

to organisations representing minority ethnic groups, the lesbian, gay, bisexual, transgender, and questioning (or queer) (LGBTQ) community, women's groups and faith-based organizations. Each of these will be affected by age-related issues in different ways: their involvement could make a substantial contribution to creating a more inclusive and representative age-friendly movement.

A related observation made by Lehning et al. (2017: 53) also applies to the age-friendly programmes in Brussels, Dublin and Manchester studied here, in that they, to a greater or lesser extent, have "failed to address the specific needs of racial and ethnic minorities or those with low incomes." The authors go further to note that: "this is of particular concern, given these subgroups of older adults are likely to live in particularly un-aging-friendly, under resourced neighborhoods." More generally, the social exclusion experienced by many groups in urban areas - notably migrants, refugees and those living in communities with high levels of deprivation - has been neglected in discussions about the development of age-friendly policies (Buffel \& Phillipson 2018). Acknowledging social and ethnic diversity is therefore an important issue for the age-friendly movement to address. The implications are wide-ranging, including responding to different cultural interpretations of what "age-friendliness" might mean; shaping policies around the needs of particular groups with contrasting migration histories and life course experiences; recognising distinctive forms of inequality experienced by particular ethnic groups, notably in areas such as health, income and housing; and understanding the impact of racism in communities and the challenge this presents for the achievement of successful age-friendly work.

A second advantage in linking age-friendly work to the goal of reducing social exclusion lies in its potential to facilitate a more active integration of age-friendliness with other major priorities within cities, increasing its relevance and harnessing its holistic approach to addressing major societal challenges. Environmental issues, sustainable development and affordable housing are all significant urban and public policy concerns that impact older people and that require new approaches and perspectives. A starting point for extending the scope of age-friendly activity would be to strengthen collaboration with the range of movements campaigning to improve urban environments. One response would be to establish links with groups working on initiatives such as "smart cities," "healthy cities," 
International Journal of Ageing and Later Life

"resilient" and "sustainable cities" (Ramaswami et al. 2016; UN-Habitat 2016). Encouraging links between different urban programmes might help expand the range of age-friendly interventions. For example, ideas from the "smart" and "sustainable" cities movement around supporting alternatives to cars, increasing energy efficiency and reducing pollution, should also be a central part of making cities "age-friendly." Engagement with this type of work has the potential to produce both further resources for the movement as well as adding to the sustainability of existing projects.

Third, harnessing social exclusion as an orientating lens will help to derive a more defined multidimensional measurement framework for determining the impact and effectiveness of age-friendly programmes - a framework that is underpinned by a conceptual, practical and political understanding already evident across policy and practice spheres. This will be critical to justify funding for new age-friendly initiatives in the future, particularly in a context of economic constraint and austerity (Buffel \& Phillipson 2018; WHO 2018). It may also remove some of the ambiguity around what age-friendly initiatives are attempting to achieve, and offer a focal point for measuring impact and prioritising interventions in the context of complex real life challenges for disadvantaged and vulnerable groups. Findings from the three cities highlight an urgent need for models and tools that help measure the impact of interventions and monitor change over time. Existing efforts to assess the impact of agefriendly initiatives are hampered by the lack of an adequate logic model specifying what inputs and interventions are hypothesised to produce particular outcomes and impact. Given the need for a stronger emphasis on research, a key task for the age-friendly movement will be to create stronger linkages with academic institutions and researchers from multiple disciplinary perspectives to demonstrate the social and economic impact of the work. Whether the age-friendly approach actually makes a significant difference in reducing social exclusion will need careful attention over the next phase of the development of the movement.

Finally, the research identified a number of common barriers to implementing age-friendly initiatives across the three cities, including economic recession, bureaucratic structures and sustainability. Some of these challenges illustrate how the goal of age-friendliness has to compete with macro-level economic processes, and indeed wider objectives associated with urban development (Buffel et al. 2018; Menec et al. 2011). 
Age-friendly approaches and old-age exclusion

Others illustrate issues that influence its future existence, development and effectiveness, raising fundamental questions about sustainability. What is more, these challenges are likely to impede the capacity of agefriendly policies and practices to combat the exclusion of older people.

Although this study identifies important findings in terms of linking age-friendliness with the goal of social exclusion, there are a number of challenges arising from taking a cross-national approach that serve as limitations to our analysis. These include linguistic, social and political differences between the cities, and more practical differences relating to sampling and data collection procedures, that can have implications for the interpretation of findings. A first challenge is "inherent in its nature" in that the data were not collected to answer the secondary research questions. A second limitation of using secondary data is that the researcher is not a participant in the data collection process. However, in this study, the research team was at an advantage because they were involved in executing data collection in their respective cities. Notwithstanding these significant limitations, a key contribution of this research comes from bringing together existing qualitative data sources for new, comparative purposes in order to produce novel ways of understanding approaches to ageing and social exclusion in cities. This is especially important given the limited availability of cross-national studies examining age-friendly work. Our study highlights the potential of qualitative secondary data analysis to bring greater power to answer research questions through comparison across contexts and social groups, and to identify relevant barriers, principles and successes of age-friendly work that may foster learning and exchange between cities.

\section{Conclusion}

This article has identified various benefits linked to connecting the agefriendly approach to the goal of reducing social exclusion: first, it offers a lens for incorporating the views of seldom heard or hidden populations; second, it provides a forum for developing interdisciplinary and cross-sectorial partnerships to challenge discriminatory practice and marginalisation; and third, it provides a viable orientation and focal point for measuring the impact of age-friendly initiatives. Applying a "social exclusion" lens will not in itself resolve the problems facing older people 
International Journal of Ageing and Later Life

subject to economic and social change. However, it does provide the basis of a programme of action in which age-friendly activities can be an important part of policies improving the communities in which people live.

\section{Funding}

This work was supported by the Economic and Social Research Council (ESRC) under the Future Research Leaders scheme (Grant No: ES/ N002180/1); the Social Sciences and Humanities Research Council of Canada (SSHRC) through a Doctoral Fellowship at the University of Manchester; Manchester City Council and The Atlantic Philanthropies (grant no. 22072) and the European Cooperation in Science and Technology (COST Action 15122) through ROSEnet, Reducing Old-Age Social Exclusion: Collaborations in Research and Policy.

\section{Corresponding Author}

Tine Buffel, Sociology/Manchester Institute for Collaborative Research on Ageing (MICRA), Manchester Urban Ageing Research Group (MUARG), The University of Manchester, Bridgeford St. Building Room 2.13v, M13 9PL, Manchester, UK. Email: tine.buffel@manchester.ac.uk

\section{References}

Bowen, G. A. (2009). Document analysis as a qualitative research method. Qualitative Research Journal 9(2): 27-40.

Buffel, T., Handler, S. \& Phillipson, C. (eds.) (2018) Age-Friendly Communities: A Global Perspective. Bristol: Policy Press.

Buffel, T., McGarry, P., Phillipson, C., De Donder, L., Dury, S., De Witte, N., Smetcoren, A. S. \& Verté, D. (2014) Developing age-friendly cities: Case studies from Brussels and Manchester and implications for policy and practice. Journal of Aging \& Social Policy 26: 52-72.

Buffel, T. \& Phillipson, C. (2016) Can global cities be "age-friendly cities"? Urban development and ageing populations. Cities, 55:94-100.

Buffel, T. \& Phillipson, C. (2018) A manifesto for the age-friendly movement: Developing a new urban agenda. Journal of Aging \& Social Policy 30(2):173-192. 
Corti, L., Witzel, A. \& Bishop, L. (eds.) (2005). Secondary Analysis of Qualitative Data. Available on http://www.qualitative-research.net/index. $\mathrm{php} / \mathrm{fqs} /$ issue/view/13 (Accessed: November 30, 2019).

De Tavernier, W. \& Aartsen, M. (2019). Old-age exclusion: Active ageing, ageism and agency. Social Inclusion 7(3): 1-3 doi: 10.17645/si.v7i3.2372.

Dublin Age Friendly City (2014). Dublin Age Friendly City Strategy 20142019. Dublin City Council. Available on http://www.dublincity.ie/ sites/default/files/content/Community/AgeFriendlyCityProject/Documents/DCCAgeFriendlyFAweb.pdf (Accessed: November 11, 2019).

Eurostat. (2017). Key figures on Europe. Luxembourg: Publications office of the EU.

Golant, S. M. (2014). Age-Friendly Communities: Are We Expecting Too Much? IRPP Insight 5. Montreal: Institute for Research on Public Policy.

Gonyea, J. G. \& Hudson, R. B. (2015). Emerging models of age-friendly communities: A framework for understanding inclusion. Public Policy \& Aging Report 25(1): 9-14.

Grenier, A. (2007). Constructions of frailty in the English language, care practice and the lived experience. Ageing $\mathcal{E}$ Society 27(3): 425-445.

Hantrais, L. (2009). International Comparative Research: Theory, Methods and Practice. Basingstoke: Palgrave Macmillan.

Lehning, A. J., Smith, R. J. \& Kyeongmo, K. (2017). "Friendly" initiatives: An emerging approach to improve communities for vulnerable populations. Journal of Policy Practice 16: 46-58.

Levitas, R., Pantazis, C., Fahmy, E., Gordon, D., Lloyd, E. \& Patsios, D. (2007). The Multi-Dimensional Analysis of Social Exclusion. Bristol: University of Bristol.

McGarry, P. (2018). Developing age-friendly policies for cities: Strategies, challenges and reflections. In T. Buffel, S. Handler \& C. Phillipson (eds.), Age-friendly Cities and Communities: A Global Perspective (pp. 231-250). Bristol: Policy Press.

Menec, V. H., Means, R., Keating, N., Parkhurst, G. \& Eales, J. (2011). Conceptualizing age-friendly communities. Canadian Journal on Aging 30(3): 479-493.

McDonald, B., Scharf, T. \& Walsh, K. (2018) Creating an age-friendly county in Ireland: Stakeholders' perspectives on implementation. In T. Buffel, S. Handler, C. Phillipson (eds.), Age-Friendly Cities and Communities: A Global Perspective (pp. 143-166). Bristol: Policy Press. 
International Journal of Ageing and Later Life

Moulaert, T. \& Garon, S. (eds.) (2016). Age-Friendly Cities and Communities in International Comparison: Political lessons, Scientific Avenues, and Democratic Issues. Cham: Springer International.

Nazroo, J. (2017). Class and health inequality in later life: Patterns, mechanisms and implications for policy. International Journal of Environmental Research and Public Health 14: 1533. doi: 10.3390/ijerph14121533

Patton, M. Q. (2002). Two decades of developments in qualitative inquiry: A personal, experiential perspective. Qualitative Social Work 1: 261-283.

Phillipson, C. (2007). The "elected" and the "excluded": Sociological perspectives on the experience of place and community in old age. Ageing \& Society 27(3): 321-342.

Prattley, J., Buffel, T., Marshall, A. \& Nazroo, J. (2020). Area effects on the level and development of social exclusion in later life. Social Science $\mathcal{E}$ Medicine 246: 112722.

Precupetu, L., Aartsen, M. \& Vasile, M. (2019). Social exclusion and mental wellbeing in older Romanians. Social Inclusion 7(3):4-16. doi: 10.17645/ si.v7i3.2008

Ramaswami, A., Russel, A. G., Culligan, P. J., Sharma, K. R. \& Kumar, E. (2016). Meta-principles for developing smart, sustainable, and healthy cities. Science 352(6288): 940-943.

Rémillard-Boilard, S. (2019). Developing Age-Friendly Cities: A Public Policy Perspective. Doctoral thesis. Manchester: The University of Manchester.

Rapley, T. (2013). Sampling strategies in qualitative research. In U. Flick (ed.) The Sage Handbook of Qualitative Data Analysis (pp. 49-63). London: Sage.

Ruggiano, N. \& Perry, T. E. (2019). Conducting secondary analysis of qualitative data: Should we, can we, and how? Qualitative Social Work 18(1): 81-97.

Scharf, T., Phillipson, C. \& Smith, A. E. (2005). Social exclusion of older people in deprived urban communities of England, European Journal of Ageing 2(2): 76-78.

Scharf, T. \& Shaw, C. (2017). Inequalities in Later Life. London: Centre for Ageing Better.

Scharlach, A. E. (2017). Aging in context: Individual and environmental pathways to aging-friendly communities. The Gerontologist 57(4): 606-618. 
Age-friendly approaches and old-age exclusion

Scharlach, A. E. \& Lehning, A. J. (2013). Ageing-friendly communities and social inclusion in the United States of America. Ageing \& Society 33(1): 110-136.

Silverman, D. (2006). Interpreting Qualitative Data: Methods for Analyzing Talk, Text and Interaction. London: Sage.

Steels, S. (2015). Key characteristics of age-friendly cities and communities: A review. Cities 47: 45-52.

UN-Habitat. (2016). World Cities. Nairobi: United Nations Human Settlements Programme.

United Nations. (2019). The Sustainable Development Goals Report. New York: United Nations.

Van Regenmortel, S., De Donder, L., Dury, S., Smetcoren, A. S., De Witte, N. \& Verté, D. (2016). Social exclusion in later life: A systematic review of the literature. Journal of Population Ageing 9(4): 315-344.

Walsh, K. (2018). Evaluation of Phase 1 of the Dublin City Age Friendly Housing with Support Model in Inchicore. Dublin: The Housing Agency.

Walsh, K. (2015). Integrating the 'age-friendly community' in austerity: myths, realties and the influence of place context. In K. Walsh, G. Carney \& A. Ni Leime (eds.), Ageing through Austerity: Critical Perspectives from Ireland. Bristol: Policy Press.

Walsh, K., Scharf, T. \& Keating, N. (2017) Social exclusion of older persons: A scoping review and conceptual framework. European Journal of Ageing 14(1): 81-98.

Wanka, A., Moulaert, T. \& Drilling, M. (2018). From environmental stress to spatial expulsion - Rethinking concepts of socio-spatial exclusion in later life. International Journal of Ageing and Later Life 12(2): 25-51.

White, S., Phillipson, C., Aftam, F. \& Hammond, M. (2013). Old Moat: AgeFriendly Neighbourhood Report. Manchester: Southway Housing.

World Health Organization. (2007). Global Age-Friendly Cities: A Guide. Geneva: WHO.

World Health Organization. (2018). The Global Network for Age-Friendly Cities and Communities: Looking back over the Last Decade, Looking Forward to the Next. Geneva: WHO.

Yin, R. K. (2002). Case study Research: Design and Methods. Thousand Oaks, CA: Sage. 
